\title{
A Study on Relationship between Depression and Subjective Well-Being of College Student
}

\author{
Xiao Zheng \\ Ideological and Political Theory Class Teaching and Research Department, Eastern Liaoning University, \\ Dandong, China \\ Email: 157260784@qq.com
}

Received 25 April 2016; accepted 17 June 2016; published 21 June 2016

Copyright (C) 2016 by author and Scientific Research Publishing Inc.

This work is licensed under the Creative Commons Attribution International License (CC BY).

http://creativecommons.org/licenses/by/4.0/

(c) (i) Open Access

\begin{abstract}
The current research aimed to explore the relationship between depression, the social support and subjective well-being using questionnaire survey. The results showed that the social support, depression and subjective well-being were significantly related. It is found that the depression and the sense of subjective well-being of students play a role of predictive by regression analysis.
\end{abstract}

\section{Keywords}

\section{College Students, Social Support, Depression, Subjective Well-Being}

\section{Introduction}

Subjective well-being (SWB) refers to how people experience the quality of their lives and includes both emotional reactions and cognitive judgments (Diener, 1984), it is an important psychological standard to measure the quality of individual's life. For a long time, psychological researchers have mainly focused on the prevention, diagnosis and treatment of mental disorders and psychological disorders. They pay particular attention to the impact of depression, anxiety, compulsion and other negative emotions on people, hoping to improve people's quality of life by reducing people's negative psychology. The research of college students also is such, most of the studies focus on the negative emotions and behavior of college students, such as anxiety, depression, obsessive etc. However, the mental health not only means less negative factors, but also positive factors, for instance, happiness, pleasure and satisfaction, etc. Positive psychology is particularly concerned with the study of SWB (Zung, 1986). Subjective well-being can be seen as an important factor of measuring the psychological state and quality of life. A meta-analysis found that self-ratings of general health were more strongly related to SWB than physician ratings of health (Okun, Stock, Haring, \& Witter, 1984). Many researchers have conducted some studies 
on the subjective well-being, indicating that the elements affecting subjective well-being includes personality, self-esteem, life events, handling methods and so on. This essay focuses on the effects of the social support and depression on subjective well-being, aiming to improve the level of mental health of contemporary undergraduates.

\section{Objects and Methods}

\subsection{Participants}

We used unified guidance language to measure the unit of university. All participants had signed the informed consent. The time of measurement is 20 minutes, and the questionnaires are collected after the measurement. We distributed 912 questionnaires in total and collected 870 of them. Besides those 42 incomplete and invalid ones, we have 870 available questionnaires and the effective rate is $90.6 \%$. The Participants were from a large comprehensive university in Dalian, mainland China. With both the mean and the median being 20 years, the students' ages ranged from 18 to 27. Of all participants, 245 were first-year students, 383 were second-year students, and 242 were third-year students.

\subsection{Research Tools}

\subsubsection{General Well-Being Schedule (GWB)}

GWB (Wang, Wang, Ma et al., 1998) is consisting of 33 items and is divided into 6 dimensions which include worries about health, vigor, life satisfaction and interests, sad or happy state of mind, control of emotions and behaviors, relaxation and stress. Because the items from 19 - 33 were used to measure the people who had the tendency of nervous breakdown, and the items from 1 - 18 had been used in China to measure the subjective well-being in many occupations. So, the items from 1 - 18 of this scale were chosen in this research as tools to measure the level of subjective well-being. The items 2, 5, 6, 7 used 5 points, with ranging from " 1 " representing "very bad" to " 5 " representing "very good". The other 14 items used 6 points, with ranging from " 1 " representing "extremely bad" to "6" representing "extremely good". 9 items were reversely scored, which included $1,3,6,7,9,11,13,15,16$. Higher score indicates higher level of subjective well-being. In this study, the Cronbach's alpha of this scale was 0.846 .

\subsubsection{Self-rating Depressive Scale (SDS)}

The Chinese version of the SDS is a self-report measure of depression, which is composed of 20 items, with a four-point scale ranging from a little of the time (1) to most of the time (4). Of the 20 items, 10 are worded positively and 10 are worded negatively. The former 10 items are reversed items. The validity and the reliability of the SDS have been reported (for review, see Zung, 1986).

\subsubsection{Social Support Rating Scale (SSRS)}

This research adopted Social Support Rating Scale (SSRS) formulated by Xiao Shuiyuan. This scale includes objective support, subjective support and the availability of support. In our research, according to the actual situation, replacing "colleagues" by "colleagues and classmates" and replacing "spouses" by "spouses and lovers". After three weeks we used the revision to measure again to small sample, the results was the correlation coefficient of ten items is 0.69 to 0.91 . In this research Cronbach's alpha of this scale is 0.851 , split-half reliability is 0.694 .

\subsection{Statistical Analysis}

Data was analyzed using SPSS 13.0 for Windows. Correlation analysis between subjective well-being, depression, and social support were calculated to indicate the level of association between these variables. Regression analysis is used to discuss the impact of social support on depression and subjective well-being

\section{Results}

\subsection{The Correlation Analysis between the Social Support, Depression and Subjective Well-Being}

Table 1 is the results for the correlation analysis between subjective well-being, depression, and social support 
Table 1. The correlation analysis between the social support, depression and subjective well-being.

\begin{tabular}{cccccc}
\hline & $\begin{array}{c}\text { Social Support } \\
\text { In total }\end{array}$ & $\begin{array}{c}\text { Objective } \\
\text { support }\end{array}$ & $\begin{array}{c}\text { Subjective } \\
\text { support }\end{array}$ & $\begin{array}{c}\text { The availability } \\
\text { of support }\end{array}$ & Depression \\
\hline Objective support & $0.832^{* *}$ & - & - & - & - \\
Subjective support & $0.872^{* *}$ & $0.509^{* *}$ & - & - & - \\
The availability of support & $0.479^{* *}$ & $0.194^{*}$ & $0.323^{* *}$ & - & $-0.194^{*}$ \\
Depression & $-0.242^{* *}$ & $-0.175^{*}$ & $-0.207^{*}$ & $0.220^{*}$ & $-0.633^{* *}$ \\
Subjective well-being & $0.279^{* *}$ & $0.229^{* *}$ & $0.213^{*}$ & & \\
\hline
\end{tabular}

Note: ${ }^{*}$ Refers to $P<0.05 ;{ }^{* *}$ Refers to $P<0.01 ;{ }^{* * *}$ Refers to $P<0.001$.

Table 2. The regression analysis between the social support, depression and subjective well-being.

\begin{tabular}{ccccccc}
\hline Dependent variable & Independent variable & $\beta$ & $\mathrm{t}$ & $\mathrm{R} 2$ & $\Delta \mathrm{R} 2$ & $\mathrm{~F}$ \\
\hline Subjective well-being & Depression & -0.633 & -9.206 & 0.400 & 0.396 & $84.78^{* *}$ \\
\hline
\end{tabular}

(objective support, subjective support, The availability of support), showing a significantly positive correlation between the three dimensions of social support, a significantly negative correlation between the three dimensions of social support and depression, a significantly positive correlation between the three dimensions of social support and subjective well-being, and a significantly negative correlation between depression and subjective well-being.

\subsection{The Regression Analysis between the Social Support, Depression and Subjective Well-Being}

To further discuss the impact of social support on depression and subjective well-being, regarding social support and depression as predictor variables, and subjective well-being as dependent variable, stepwise regression is used to process multivariate regression analysis. The results are shown in Table 2. Only depression is involved in the regression equation, and concomitant probability $\mathrm{F}$ reaches to a significant level, indicating that positive response towards college students' Subjective well-being has linear relationship and regression results are obvious.

\section{Discussions}

Through this study, we found that subjective well-being of college students is positively correlated with social support, and negatively correlated with depression, which were accorded with the results of previous researches on primary (Kaczmarek, 2014; Gallagher \& Vella-Brodrick, 2008; Yuan 2010). Social support and subjective well-being are closely related, whether the individual has an objective support source, the subjective feeling of support, or the utilization of support, all has significant relevance with indexes of subjective well-being. Good social support, results more positive emotions in their experience, more satisfying life experience, and an overall higher level self-experience of happiness. It can explain why the enhancement of students' social support and the reducing of their depression can help improve students' level of happiness. Further regression analysis finds that depression and subjective well-being has a close relationship, and can better predict happiness. That is consistent with the results of previous researches (Ahmad, Aftab, \& Rizwan, 2007). The result shows that students with low depression have higher subjective well-being.

\section{References}

Ahmad, R., Aftab, S., \& Rizwan, M. (2007). Subjective Well-Being and Depression: A Correlational Study. [Kangogijutsu]: [Nursing Technique], 6, 63-76.

Diener, E. (1984). Subjective Well-Being. Psychological Bulletin, 95, 542-575. http://dx.doi.org/10.1037/0033-2909.95.3.542

Gallagher, E. N., \& Vella-Brodrick, D. A. (2008). Social Support and Emotional Intelligence as Predictors of Subjective Well-Being. Personality \& Individual Differences, 44, 1551-1561. http://dx.doi.org/10.1016/j.paid.2008.01.011 
Kaczmarek, L. D. (2014). Subjective Well-Being as a Mediator between Curiosity and Depression. Polish Psychological Bulletin, 45, 200-204. http://dx.doi.org/10.2478/ppb-2014-0025

Okun, M. A., Stock, W. A., Haring, M. J., \& Witter, R. A. (1984). Health and Subjective Well-Being: A Meta-Analysis. International Journal of Aging \& Human Development, 19, 111-132. http://dx.doi.org/10.2190/QGJN-0N81-5957-HAQD

Yuan, L. X. (2010). The Relationships between Depression, Subjective Well-Being (SWB) and Emotional Intelligence of Undergraduates. Journal of Guangdong Education Institute, 30, 49-53.

Zung, W. W. K. (1986). Zung Self-Rating Depression Scale and Depression Status Inventory. In N. Sartorius, \& T. A. Ban (Eds.), Assessment of Depression (Reprinted, pp. 221-231). Berlin, Heidelberg: Springer Berlin Heidelberg.

\section{Submit or recommend next manuscript to SCIRP and we will provide best service for you:}

Accepting pre-submission inquiries through Email, Facebook, Linkedin, Twitter, etc A wide selection of journals (inclusive of 9 subjects, more than 200 journals)

Providing a 24-hour high-quality service

User-friendly online submission system

Fair and swift peer-review system

Efficient typesetting and proofreading procedure

Display of the result of downloads and visits, as well as the number of cited articles

Maximum dissemination of your research work

Submit your manuscript at: http://papersubmission.scirp.org/ 